\title{
Gestational diabetes: risks, management, and treatment options
}

\author{
This article was published in the following Dove Press journal: \\ International Journal of Women's Health \\ 5 October 2010 \\ Number of times this article has been viewed
}

\section{Catherine Kim \\ Departments of Medicine and Obstetrics and Gynecology, University of Michigan, Ann Arbor, MI, USA}

\begin{abstract}
Gestational diabetes mellitus (GDM) is commonly defined as glucose intolerance first recognized during pregnancy. Diagnostic criteria for GDM have changed over the decades, and several definitions are currently used; recent recommendations may increase the prevalence of GDM to as high as one of five pregnancies. Perinatal complications associated with GDM include hypertensive disorders, preterm delivery, shoulder dystocia, stillbirths, clinical neonatal hypoglycemia, hyperbilirubinemia, and cesarean deliveries. Postpartum complications include obesity and impaired glucose tolerance in the offspring and diabetes and cardiovascular disease in the mothers. Management strategies increasingly emphasize optimal management of fetal growth and weight. Monitoring of glucose, fetal stress, and fetal weight through ultrasound combined with maternal weight management, medical nutritional therapy, physical activity, and pharmacotherapy can decrease comorbidities associated with GDM. Consensus is lacking on ideal glucose targets, degree of caloric restriction and content, algorithms for pharmacotherapy, and in particular, the use of oral medications and insulin analogs in lieu of human insulin. Postpartum glucose screening and initiation of healthy lifestyle behaviors, including exercise, adequate fruit and vegetable intake, breastfeeding, and contraception, are encouraged to decrease rates of future glucose intolerance in mothers and offspring.
\end{abstract}

Keywords: glucose intolerance, pregnancy, perinatal complications

\section{Introduction}

Gestational diabetes mellitus (GDM) is commonly defined as glucose intolerance first recognized during pregnancy. ${ }^{1}$ The prevalence of GDM is increasing, fueled by advancing maternal age, racial/ethnic shifts in childbearing, and obesity. ${ }^{2}$ Several studies, including the Hyperglycemia and Adverse Pregnancy Outcomes (HAPO) Study, ${ }^{3}$ the Australian Carbohydrate Intolerance in Pregnancy (ACHOIS) randomized trial, ${ }^{4}$ and the Metformin in Gestational Diabetes (MiG) randomized trial, ${ }^{5}$ have helped clarify several diagnostic and treatment issues, while raising additional questions. In this article, the current thinking regarding screening and diagnosis, complications, and management options for GDM are reviewed.

\section{Diagnosis of GDM}

Diagnostic criteria for GDM have changed over the decades, and several definitions are currently used. The reasons for this variation are rich and complicated, reflecting declines in perinatal mortality, advances in assay technology, evolving access to care, epidemiology, and local cultural practices. For an excellent summary of the early history of GDM, the reader is referred to Hadden's essay ${ }^{6}$ outlining screening guidelines
Correspondence: Catherine Kim

300 North Ingalls Building, Room 7CI3,

Ann Arbor, MI 48I09-5429, USA

Tel +l 7349365216

Fax +I 7349368944

Email cathkim@umich.edu 
and diagnostic cutpoints from more recent times, which are illustrated in Table 1.

The American Diabetes Association (ADA) recommends screening for GDM at the time of pregnancy diagnosis if any of the following conditions are present: severe obesity, prior history of GDM or delivery of an infant that is large for gestational age (LGA), glycosuria, polycystic ovarian syndrome, or family history of type 2 diabetes. $^{7}$ If these risk factors are not present, women are to undergo diabetes screening at 24-28 weeks' gestation if any of the following conditions are present: age $\geq 25$ years, overweight before pregnancy, nonwhite race/ethnicity, family history of diabetes, history of abnormal glucose tolerance, or history of poor obstetric outcome. The American College of Obstetrics and Gynecology (ACOG) has similar recommendations. ${ }^{8}$ In contrast, the World Health Organization recommends universal screening of all women for GDM at 24-28 weeks' gestation. ${ }^{9}$

To resolve the questions regarding optimal diagnostic cutpoints, the National Institutes of Health and other health care organizations sponsored HAPO, an international prospective cohort study. ${ }^{3}$ Approximately 25,000 pregnant women underwent a $75 \mathrm{~g}$ oral glucose tolerance test (OGTT) and careful assessment of perinatal outcome measures, with blinding of caregivers and subjects. Women with particularly elevated glucose levels were unblinded and treated. The final study cohort includes only women with glucose values for which risk of adverse outcomes was uncertain.

The study found that the risk of adverse pregnancy outcomes increased continuously with glucose levels. ${ }^{3}$ Primary outcomes included birthweight above the 90th percentile for gestational age, cesarean delivery, clinical neonatal hypoglycemia, and cord serum C-peptide values above the 90th percentile. Secondary outcomes included preterm delivery (less than 37 weeks' gestation), sum of skinfolds above the 90th percentile for gestational age, percent body fat greater than the 90th percentile for gestational age, admission to neonatal intensive care, hyperbilirubinemia, pre-eclampsia, and birthweight under the 10th percentile for gestational age.

Table I Screening guidelines from the American Diabetes Association (ADA), ${ }^{7}$ the American College of Obstetrics and Gynecology (ACOG), ${ }^{8}$ the World Health Organization (WHO), ${ }^{9}$ and the Hyperglycemia and Adverse Pregnancy Outcomes Study Group $(\mathrm{HAPO})^{10}$

\begin{tabular}{|c|c|c|c|}
\hline ADA & ACOG & WHO & HAPO \\
\hline Strategy I & Strategy I & Strategy I & Strategy I \\
\hline $\begin{array}{l}\text { During a } 100 \mathrm{~g} \text { glucose challenge, } \\
\text { exceeds } 2 \text { of the following: }\end{array}$ & $\begin{array}{l}\text { After a } 50 \mathrm{~g} \text { glucose challenge, } \\
\text { exceeds } 130-140 \mathrm{mg} / \mathrm{dL} \\
(7.2-7.8 \mathrm{mM} / \mathrm{L})\end{array}$ & $\begin{array}{l}\text { During a } 75 \mathrm{~g} \text { challenge, } \\
\text { exceeds I of the following: }\end{array}$ & $\begin{array}{l}\text { During a } 75 \mathrm{~g} \text { glucose challenge, } \\
\text { exceeds I of the following: }\end{array}$ \\
\hline fasting $\geq 95 \mathrm{mg} / \mathrm{dL}(5.3 \mathrm{mM} / \mathrm{L})$ & AND & fasting $\geq 126 \mathrm{mg} / \mathrm{dL}(7.0 \mathrm{mM} / \mathrm{L})$ & fasting $\geq 92 \mathrm{mg} / \mathrm{dL}(5.1 \mathrm{mM} / \mathrm{L})$ \\
\hline I-hour $\geq 180$ mg/dL (10 mM/L) & $\begin{array}{l}\text { During a } 100 \mathrm{~g} \text { glucose challenge, } \\
\text { exceeds } 2 \text { of the following: }\end{array}$ & $\begin{array}{l}\text { 2-hour glucose } \geq 140 \mathrm{mg} / \mathrm{dL} \\
(7.8 \mathrm{mM} / \mathrm{L})\end{array}$ & $\mathrm{I}$-hour $\geq 180 \mathrm{mg} / \mathrm{dL}(10 \mathrm{mM} / \mathrm{L})$ \\
\hline 2-hour $\geq 155 \mathrm{mg} / \mathrm{dL}(8.6 \mathrm{mM} / \mathrm{L})$ & fasting $\geq 95 \mathrm{mg} / \mathrm{dL}(5.3 \mathrm{mM} / \mathrm{L})$ & & 2-hour $\geq 153 \mathrm{mg} / \mathrm{dL}(8.5 \mathrm{mM} / \mathrm{L})$ \\
\hline 3-hour $\geq 140 \mathrm{mg} / \mathrm{dL}(7.8 \mathrm{mM} / \mathrm{L})$ & $\begin{array}{l}\text { I-hour } \geq 180 \mathrm{mg} / \mathrm{dL}(10 \mathrm{mM} / \mathrm{L}) \\
2 \text {-hour } \geq 155 \mathrm{mg} / \mathrm{dL}(8.6 \mathrm{mM} / \mathrm{L})\end{array}$ & & \\
\hline OR & 3-hour $\geq 140$ mg/dL (7.8 mM/L) & & \\
\hline Strategy 2 & OR & & \\
\hline \multicolumn{4}{|l|}{$\begin{array}{l}\text { After a } 50 \mathrm{~g} \text { glucose challenge, } \\
\text { exceeds } 130-140 \mathrm{mg} / \mathrm{dL}\end{array}$} \\
\hline (7.2-7.8 mM/L) & Strategy 2 & & \\
\hline AND & After a $50 \mathrm{~g}$ glucose challenge, & & \\
\hline \multirow[t]{3}{*}{ then fails Strategy I } & exceeds $130-140 \mathrm{mg} / \mathrm{dL}$ & & \\
\hline & $(7.2-7.8 \mathrm{mM} / \mathrm{L})$ & & \\
\hline & AND & & \\
\hline OR & During a $100 \mathrm{~g}$ glucose & & \\
\hline Strategy 3 & challenge, & & \\
\hline During a 75 g challenge, & exceeds 2 of the following: & & \\
\hline exceeds I of the following: & fasting $\geq 105 \mathrm{mg} / \mathrm{dL}(5.8 \mathrm{mM} / \mathrm{L})$ & & \\
\hline fasting $\geq 95 \mathrm{mg} / \mathrm{dL}(5.3 \mathrm{mM} / \mathrm{L})$ & I-hour $\geq 190 \mathrm{mg} / \mathrm{dL}(10.6 \mathrm{mM} / \mathrm{L})$ & & \\
\hline I-hour glucose $\geq 155 \mathrm{mg} / \mathrm{dL}(8.6 \mathrm{mM} / \mathrm{L})$ & 2 -hour $\geq 165 \mathrm{mg} / \mathrm{dL}(9.2 \mathrm{mM} / \mathrm{L})$ & & \\
\hline 2-hour glucose $\geq 140 \mathrm{mg} / \mathrm{dL}(7.8 \mathrm{mM} / \mathrm{L})$ & 3 -hour $\geq 145 \mathrm{mg} / \mathrm{dL}(8.0 \mathrm{mM} / \mathrm{L})$ & & \\
\hline
\end{tabular}


Subsequently, the International Association of Diabetes and Pregnancy Study Groups (IADSPG) consensus panel members defined glucose cutpoints for GDM as those associated with odds ratios (OR) of 1.75 for perinatal risks compared with mean glucose values. ${ }^{10}$ These cutpoints are illustrated in Table 1, along with guidelines from several other organizations. At the time of writing, these other health care organizations are considering an endorsement of these recommendations. One of the implications is that many more women will be diagnosed with GDM, and the subsequent effects regarding their care and demands on health care resources are unknown. Lawrence et al have estimated that approximately $20 \%$ of pregnant women in the Kaiser Permanente Southern California health care system would be diagnosed with GDM if HAPO criteria were applied. ${ }^{11}$

\section{Risks of GDM-related perinatal complications}

In a review from $1991,{ }^{12}$ O'Sullivan observed, "Although the variability in diabetes incidence rates is wide, there is broad general agreement on the predictive nature of gestational blood glucose levels". This statement still holds for both fetal and maternal complications. In recent years, there has been increased attention paid to the substantial overlap in complications of GDM and obesity during pregnancy. ${ }^{13}$ This attention has been focused by changes in the recommendations for weight changes during pregnancy, ${ }^{14}$ along with the steady rise in obesity in industrialized countries. Complications associated with GDM may be, at least in part, explained by the increased body mass index (BMI) of GDM women. While there are women who do not meet BMI criteria for obesity but are nevertheless "metabolically obese", the overwhelming majority of women with GDM are overweight or obese. ${ }^{15}$ In the following paragraphs, the most common morbidities of GDM are reviewed. When possible, a distinction is made between complications associated with obesity as compared with those associated with abnormal glucose levels.

\section{Hypertensive disorders}

Women with GDM have an increased incidence of hypertensive disorders during pregnancy, including gestational hypertension, chronic hypertension, pre-eclampsia, and eclampsia. The prevalence of these disorders varies slightly across studies. In HAPO, which included women with and without GDM, approximately $2.5 \%$ of women had chronic hypertension (582 of 23,316 women), 5.9\% had gestational hypertension, and $4.8 \%$ had pre-eclampsia. ${ }^{16}$ Similarly in the randomized MiG trial, which only included GDM women, about $5.0 \%$ of women had gestational hypertension and $6.3 \%$ had pre-eclampsia. ${ }^{5}$ However, the randomized ACHOIS trial reported that $15 \%$ of its GDM population had pre-eclampsia, notably higher than other prospective studies. ${ }^{4}$

Currently, it is not known whether the overlap in GDM and hypertensive disorders reflects a common causal pathway. Both GDM and hypertensive disorders are associated with factors such as insulin resistance, inflammation, and maternal fat deposition patterns. ${ }^{17}$ In HAPO,${ }^{16}$ increased glucose levels on the index OGTT were associated with a greater risk of pre-eclampsia, even after adjustment for factors including maternal age, BMI, height, smoking status, alcohol use, family history of diabetes, gestational age at the time of the index OGTT, infant gender, parity, and cord plasma glucose. Of note, elevations in all glucose levels, ie, fasting glucose (adjusted OR, 1.21; 95\% confidence interval [CI]: 1.13-1.29), 1-hour glucose (adjusted OR, 1.28; 95\% CI: 1.20-1.37), and 2-hour glucose (adjusted OR, 1.28; 95\% CI: $1.20-1.37)$ were associated with greater odds of pre-eclampsia.

Although the causality of GDM and hypertensive disorders is not clear, pregnancies affected by both GDM and chronic hypertension have higher rates of induction of labor compared with pregnancies affected by GDM alone $(36.7 \%$ versus $6.6 \%) .{ }^{18}$ Other perinatal outcomes, such as the incidence of small-forgestational-age or LGA deliveries, do not seem to be exacerbated by the presence of both GDM and hypertension. ${ }^{18}$

\section{Preterm delivery}

Preterm delivery is usually defined as delivery $<37$ weeks' gestation. ${ }^{19}$ While acknowledged as a risk of GDM, spontaneous preterm delivery is less common compared with other adverse outcomes. In the HAPO study, approximately 1608 of the 23,316 participants (6.9\%) experienced preterm delivery (both induced and spontaneous), compared with $9.6 \%$ of infants who were LGA and $8.0 \%$ of infants who underwent intensive neonatal care admission. ${ }^{3}$ Moreover, of the primary and secondary outcomes examined in HAPO, preterm delivery had minimal association with fasting glucose levels after consideration of multiple factors noted earlier, as well as maternal blood pressure (adjusted OR, 1.05; 95\% CI: 0.99-1.11). Associations with the 1-hour glucose level (adjusted OR, 1.18; 95\% CI: 1.12-1.25) and the 2-hour glucose level (adjusted OR, 1.16; 95\% CI: 1.10-1.23) were statistically significant, but relatively weak compared with the associations between glucose levels and other outcomes. 
The association between GDM and preterm delivery may be partially explained by the coexistence of other conditions with GDM that may lead to indicated or induced preterm delivery. Such conditions include pre-eclampsia and hypertensive-associated conditions, such as intrauterine growth restriction and placental abruption. However, spontaneous preterm birth, or birth in the absence of conditions prompting medical intervention, accounts for approximately three-quarters of preterm births and is not associated with GDM.,19

\section{Shoulder dystocia}

Shoulder dystocia is usually defined as the need for additional maneuvers to deliver the shoulders if gentle traction on the fetal head does not suffice. ${ }^{20}$ In HAPO, shoulder dystocia was one of the least common outcomes, with only $1.3 \%$ of the women affected. ${ }^{3}$ While shoulder dystocia increases risk of birth trauma to the infant, these injuries are fortunately not the rule; brachial plexus palsy, which often resolves in early infancy, ${ }^{21}$ occurs in only $4 \%-13 \%$ of shoulder dystocia deliveries. ${ }^{22}$

The risk of shoulder dystocia increases with obesity and additionally with GDM. Even after consideration of maternal weight, women with glucose intolerance during pregnancy have slightly increased odds of dystocia. ${ }^{3,23}$ The increased risk conferred by GDM is thought to be related to other anthropometric abnormalities in GDM infants, particularly truncal obesity and larger shoulder diameter, as well as heavier maternal weight. In HAPO, shoulder dystocia was associated with increases in fasting glucose (adjusted OR, 1.18; 95\% CI: 1.04-1.33), 1-hour glucose (adjusted OR, 1.23; 95\% CI: 1.09-1.38), and 2-hour glucose (adjusted OR, 1.22; 95\% CI: 1.09-1.37) after adjustment for maternal BMI and height, among the other factors noted earlier.

\section{Risk of stillbirth}

Before the advent of treatment of GDM, untreated GDM was noted to increase risk of stillbirth by approximately fourfold. ${ }^{24}$ In more recent years and in industrialized nations, stillbirth is an uncommon outcome, even among women with glucose intolerance. Reduced stillbirth rates have been attributed to initiation of insulin therapy combined with closer monitoring and subsequent induction of labor as necessary. ${ }^{8}$ In a study population consisting primarily of women with GDM, the stillbirth rate was approximately 1.4 per 1000 births. ${ }^{25}$ Due to its rarity, it is difficult to assess the relationship between stillbirth and glucose levels or stillbirth and treatment in HAPO and the trials noted earlier. In HAPO, only 130 women $(0.56 \%)$ of the 23,316 deliveries experienced a perinatal death, 89 of which were fetal and 41 of which were neonatal. ${ }^{3}$ This figure was not large enough to assess the association with OGTT glucose levels.

\section{Hypoglycemia in the newborn}

Clinical hypoglycemia in the newborn is a complication of GDM, but in studies that enroll participants and thus probably involve closer monitoring than in general settings, hypoglycemia is relatively infrequent. ${ }^{8}$ In HAPO, ${ }^{3}$ clinical hypoglycemia was diagnosed on the basis of treatment with intravenous glucose infusion or low levels of glucose, defined as $<30.6 \mathrm{mg} / \mathrm{dL}$ in the first 24 hours after delivery or $45 \mathrm{mg} / \mathrm{dL}$ glucose after the first 24 hours. By these definitions, only 480 of the 23,316 women (2.1\%) had infants with clinical hypoglycemia.

The reasons for neonatal hypoglycemia include physiologic fluctuations in glucose seen in GDM women, apart from treatment. Maternal hyperglycemia is thought to lead to excess fetal glucose exposure and fetal hyperinsulinemia. ${ }^{26}$ In turn, fetal hyperinsulinemia is thought to lead to hyperplasia of fat tissue, skeletal muscle, and subsequent neonatal hypoglycemia. ${ }^{26}$ In HAPO, after adjustment for other factors mentioned earlier, infant hypoglycemia was associated with maternal one-hour glucose (adjusted OR, 1.13; 95\% CI: 1.03-1.26) and weakly associated with maternal two-hour glucose (adjusted OR, 1.10; 95\% CI: 1.00-1.12), although not significantly associated with maternal fasting glucose (adjusted OR, 1.08; 95\% CI: 0.98-1.19) on the index OGTT. ${ }^{23}$ Additional effects on infant metabolism are reviewed in more detail in the next section.

Such hypoglycemia is not necessarily worsened by the pharmacotherapy that often accompanies GDM diagnosis. In ACHOIS, the prevalence of clinical hypoglycemia was $7 \%$ in GDM receiving intervention and 5\% in GDM not receiving intervention, which was a nonsignificant difference. ${ }^{4}$ Similarly, in a multicenter randomized trial in the US, ${ }^{27}$ the prevalence of clinical neonatal hypoglycemia was similar in the intervention and control arms (5.3\% and 6.8\%, respectively).

\section{Hyperbilirubinemia}

Hyperbilirubinemia is more common among women with GDM than in women without GDM, but is still fairly infrequent. In $\mathrm{HAPO},{ }^{3}$ hyperbilirubinemia was defined as treatment with phototherapy after birth, or at least one laboratory report of a bilirubin level $\geq 20 \mathrm{mg} / \mathrm{dL}$, or readmission to the hospital for hyperbilirubinemia. Approximately $8.3 \%$ of women were affected. Maternal hyperglycemia and the subsequent induction of fetal hyperinsulinemia 
and reduced oxygenation are hypothesized to lead to increased fetal oxygen uptake, fetal erythropoiesis, and subsequent hyperbilirubinemia. ${ }^{28}$ However, other mechanisms may also be involved, given the common occurrence of hyperbilirubinemia and its relatively mild association with glucose levels; the association with fasting glucose was not significant and the associations with 1-hour glucose (adjusted OR, 1.11; 95\% CI: 1.05-1.17) and 2-hour glucose (adjusted OR, 1.08; 95\% CI: 1.02-1.13) were mild.

\section{Cesarean delivery}

Cesarean delivery has been successfully employed as an intervention used to reduce complications associated with GDM, particularly shoulder dystocia. However, as a major surgery in a gravida, it poses risks to both the fetus and the mother. Thus, the elevated rate of cesareans among GDM women can be interpreted as both an unfortunate side effect of diagnosis, as well as an appropriate response to the other morbid conditions associated with GDM, particularly shoulder dystocia and elevated fetal weight.

Cesarean deliveries are common among women with and without GDM. In HAPO, 16\% of women underwent primary cesarean sections and $7.7 \%$ underwent repeat cesarean sections. ${ }^{3}$ Elevated fasting glucose (adjusted OR, 1.11; 95\% CI: 1.06-1.15), 1-hour glucose (adjusted OR, 1.10; 95\% CI: 1.06-1.15), and 2-hour glucose (adjusted OR, 1.08; 95\% CI: 1.03-1.12) were all associated with increased odds of primary cesarean deliveries. This greater OR was after adjustment for maternal BMI and blood pressure, as well as practitioner knowledge of glucose levels. Most likely, the greater risk of cesarean is due to the other independent risk factors these women have for surgical intervention, particularly elevated fetal weight.

Whether cesarean deliveries should be routinely performed in women with elevated fetal weights is controversial, because no randomized trials exist to address this question. In the Toronto Tri-Hospital Study, women with treated GDM had a lower rate of macrosomia than women for whom glucose levels were blinded, but women with identified GDM had a two-fold increased risk of cesarean delivery. ${ }^{29}$ These findings suggest that the GDM diagnosis itself, apart from fetal weight, was an (unnecessary) risk factor for surgery. Along similar lines, whether induction should be offered in anticipation of reducing comorbidities in glucose intolerant mothers is also controversial, because no randomized trials exist. A Cochrane database review concluded that inducing glucose intolerant mothers at 38 weeks' gestation was associated with reductions in birthweight and did not increase risk of cesarean delivery, ${ }^{30}$ but delay of delivery in women with well-controlled GDM has also not been shown to be harmful.

The operation itself is associated with several maternal morbidities, particularly wound infection and dehiscence, postpartum infection and bleeding, and deep venous thrombosis, as well as the need for future cesarean section with subsequent pregnancies. ${ }^{31-33}$ These are exacerbated by the presence of obesity. Data are sparse for the complications of cesareans among GDM women and obese women. In one small study, obese women had higher infection rates if they underwent a vertical compared with transverse skin incision (34.6\% versus $9.4 \%),{ }^{34}$ although another study did not confirm these findings. ${ }^{35}$ There is also no consensus regarding subcutaneous closure and dehiscence or use of postoperative heparin therapy in obese women, although stockings are usually recommended. ${ }^{13}$

In the infant, elective delivery in late preterm or early term infants has been associated with an increase in both respiratory distress syndrome and transient tachypnea of the newborn. Although women with GDM did not independently have an increased risk of respiratory distress syndrome or tachypnea of the newborn, cesarean delivery independently increased the risk of respiratory distress syndrome (adjusted relative risk, 2.21; 95\% CI: 2.04-2.27). Risk increased with earlier gestational age. ${ }^{36}$ Accurate pregnancy dating, delaying delivery until term, and achieving euglycemia, are factors cited in the reduction of incidence of respiratory distress syndrome to less than $10 \%$ of all births. ${ }^{36}$ Partly due to the rarity of these conditions, routine assessment of fetal lung maturation after 38 weeks' gestation in GDM women is not recommended. ${ }^{1}$

\section{Risks of GDM-related metabolic complications in offspring}

The effects of GDM upon fetal health may still be conceptualized through the framework of the Pederson hypothesis, ${ }^{37}$ which postulated that intrauterine exposure could lead to permanent changes in fetal metabolism. During the GDM pregnancy, the fetus may be imprinted or programmed, resulting in excess fetal growth, decreased insulin sensitivity, and impaired insulin secretion. ${ }^{38}$ In the short term, elevated infant birthweight confers perinatal risks, such as shoulder dystocia and infant hypoglycemia. ${ }^{39}$ In the longer term, altered fetal metabolism may be associated with impaired glucose tolerance during early youth and adolescence. ${ }^{39}$

Typically, infant mass is represented by birthweight due to its ease of measurement compared with other indices which attempt to define specific components of 
weight, including fat mass. The measurement of fat mass in infants can be more difficult, as suggested by the higher coefficients of variation for other anthropometric indices compared with birthweight. ${ }^{23}$ However, several studies conducted by Catalano et al comparing infants of GDM pregnancies and infants of glucose tolerant pregnancies have demonstrated that fat mass was elevated in the GDM pregnancies, while birthweight was not necessarily elevated. ${ }^{39}$

HAPO was able to examine the incidence of LGA infants, as well as more specific anthropometric measures and their association with index glucose levels. These other measures included skin-fold thickness from the flank, subscapular region, or triceps region, and percent body fat based on measurements of total body electrical conductivity and birthweight. ${ }^{23}$ Approximately $9.6 \%$ of babies had a birthweight above the 90th percentile. The associations between glucose levels and more specific anthropometric measures of skin folds and percent body fat were not noticeably stronger than associations between glucose levels and birthweight (fasting glucose adjusted OR, 1.38; 95\% CI: 1.32-1.44, one-hour glucose adjusted OR, 1.46; 95\% CI: 1.39-1.53, two-hour glucose adjusted OR, 1.38; 95\% CI: 1.32-1.44). However, all measures were associated with cord insulin levels, consistent with the hypothesis that maternal glucose intolerance influences fetal metabolism through several pathways.

Studies regarding the association between GDM and later childhood metabolism conflict. ${ }^{40}$ The link between glucose intolerance during pregnancy and childhood weight, beyond birthweight, was first demonstrated in the Pima Indians ${ }^{41}$ then in the Northwestern Diabetes in Pregnancy Study. ${ }^{42}$ In the latter study, amniotic insulin was correlated with childhood weight. More recently, the SEARCH cohort case-control study found that youth with diabetes were more likely to have been exposed to diabetes in utero than controls. ${ }^{43}$ While the Framingham Offspring Study was unable to assess maternal exposure, it was able to examine maternal age of diabetes onset, a proxy for glucose intolerance during the reproductive years and therefore during pregnancy. ${ }^{44}$ Children whose mothers had onset of glucose intolerance when they were less than 50 years of age were more likely to have diabetes than those who did not. ${ }^{44}$

In contrast, other retrospective cohorts have not found that GDM was associated with childhood BMI beyond adjustment for infant birthweight, although in one study, information on weight was obtained from self-report and cohort retention was below $65 \% .{ }^{45}$ The presence of GDM along with elevated birthweight may exacerbate glucose intolerance associated with elevated birthweight alone. ${ }^{46}$

\section{Risks of GDM-related metabolic complications in mothers}

The link between GDM and postpartum diabetes in the mother has long been recognized. O'Sullivan's original OGTT cutpoints were based on risk of maternal diabetes, as opposed to the perinatal complications mentioned earlier. ${ }^{12}$ Approximately $5 \%-10 \%$ of cases of GDM are assumed to be previously undetected cases of diabetes, based upon background prevalence of diabetes in the population. ${ }^{47}$ The remaining and vast majority of GDM cases are attributable to the metabolic stresses of pregnancy combined with impaired insulin secretory response. ${ }^{48}$

The reduced beta-cell reserve in GDM women can manifest in the decade after delivery. ${ }^{49}$ Even among women who have a normal postpartum glucose tolerance test, the risk of future diabetes may be up to seven-fold higher than in women without histories of GDM..$^{50}$ As many as one-third of women with diabetes may have been affected by prior GDM..$^{51}$ In turn, the increased risk of diabetes is associated with future maternal cardiovascular disease..$^{52,53}$ The greater risk of cardiovascular disease seems to occur primarily in women who develop diabetes, rather in women who remain glucose-tolerant. . $2,53^{2}$

\section{Prenatal management and treatment options}

Once women are identified as having a GDM pregnancy, they are asked to engage in a management program to reduce the risks noted above. The value of identifying and treating GDM was established in the past five years with two large randomized trials, one conducted in the US through the Maternal Fetal Network ${ }^{54}$ and the other, the ACHOIS study conducted in Australia. ${ }^{4}$ It is assumed that such programs are most effectively delivered by a team of providers, specifically including nutritionists and diabetes educators, in a care delivery model similar to chronic diabetes education. ${ }^{55}$ Management during pregnancy consists of monitoring of blood glucose and medical nutrition therapy consisting of caloric restriction, physical activity, and pharmacotherapy, if glucose goals are not met. These recommendations are usually accompanied by weight management, given the high prevalence of overweight and obesity in GDM women. ${ }^{15}$ Management after pregnancy consists of postpartum screening for maternal diabetes, effective contraception that does not exacerbate underlying glucose intolerance, breastfeeding, and initiation or maintenance of healthy lifestyle behaviors. A summary of the goals for management during and after pregnancy are outlined in Table 2. 
Table 2 Recommendations for glucose and weight goals during and after pregnancy

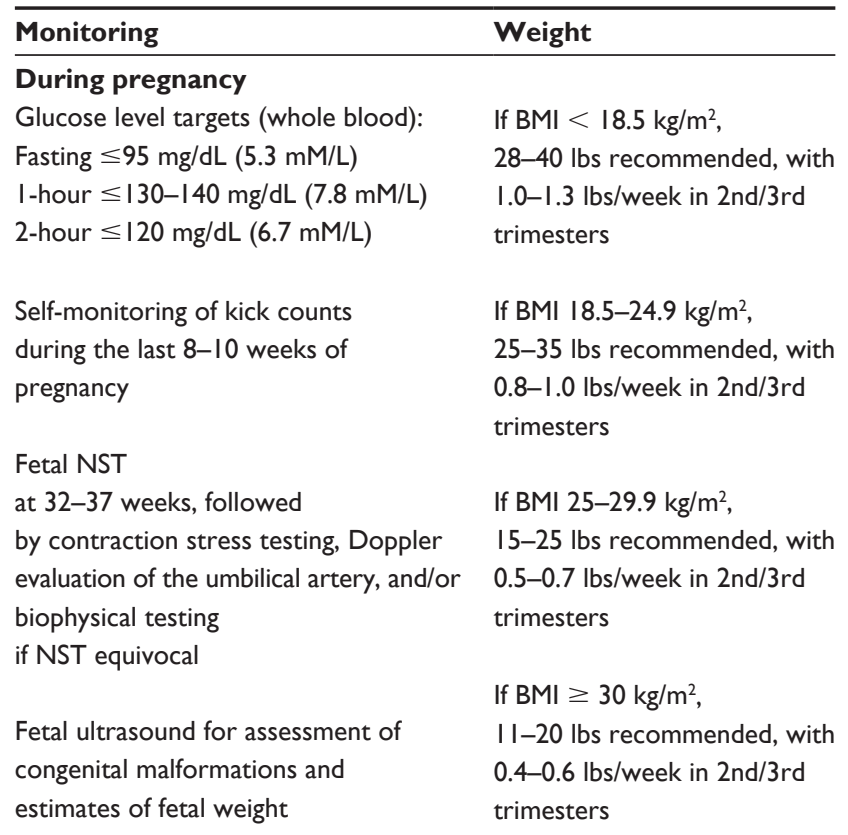

After pregnancy
Postpartum screening consisting of $\quad \mathrm{BMI}<25 \mathrm{~kg} / \mathrm{m}^{2}$
fasting glucose alone
OR
2-hour $75 \mathrm{~g}$ OGTT
Glucose level targets (plasma):
fasting $\leq 100 \mathrm{mg} / \mathrm{dL}(5.6 \mathrm{mM} / \mathrm{L})$
2-hour $\leq 140 \mathrm{mg} / \mathrm{dL}(7.8 \mathrm{mM} / \mathrm{L})$
after a $75 \mathrm{~g}$ challenge
Abbreviations: OGTT, oral glucose tolerance test; BMl, body mass index;
NST, nonstress testing.

\section{Monitoring of glucose and weight recommendations}

Guidelines for weight gain during pregnancy have been a moving target over recent decades, due to the increasing rates of obesity, as well as glucose intolerance during pregnancy. In 2010, the Institute of Medicine revised its guidelines for weight gain during pregnancy, ${ }^{14}$ and these are illustrated in Table 2. Weight goals are stratified by prepregnancy weight gain, as well as rate of weight gain in the second and third trimesters. These recommendations have been endorsed by the ADA. ${ }^{56}$ The ADA also discourages weight reduction during pregnancy in order to avoid ketosis. In general, ACOG recommends endorsing Institute of Medicine guidelines for weight, ${ }^{13}$ and ACOG has not specifically commented on the latest weight guidelines.

Weight targets are particularly emphasized if glucose goals are not met, although weight targets are also encouraged independently from glucose levels. Small reductions in weight can improve glycemic control. ${ }^{13}$ Target glucose levels recommended by $\mathrm{ACOG}^{8}$ and $\mathrm{ADA}^{7}$ are outlined in Table 2. Of note, these glucose cutpoints are higher than those noted in the HAPO study to pose risk of complications because the association between glucose and comorbidities is continuous. ${ }^{3}$

In order to determine whether these glucose targets are met, women need to engage in glucose self-monitoring or monitoring needs to be done by other means. While the ADA does not recommend a daily monitoring schedule, postprandial blood glucose measurements are emphasized over preprandial measurements. ${ }^{7}$ Urine glucose testing is not specifically recommended by the ADA but is a common practice. If women have elevated whole blood fasting glucose, ie, about $95 \mathrm{mg} / \mathrm{dL}(5.3 \mathrm{mM} / \mathrm{L})$, or if the pregnancy is postdates, additional surveillance in the form of ultrasonography is often performed for detection of asymmetric abnormal fetal growth, particularly in the third trimester, as discussed later under fetal monitoring. ${ }^{7}$

\section{Caloric intake}

The cornerstone of management of the GDM pregnancy is medical nutrition therapy. There is broad consensus that the goals of such therapy are to allow appropriate weight gain based on the mother's prepregnancy and prenatal weight, along with normoglycemia and absence of urine ketones. However, the degree of caloric restriction is not agreed upon. Short-term examination of energy restriction demonstrated that severe, ie, 50\%, energy restriction was associated with ketonemia and ketonuria even as glucose and insulin levels declined, ${ }^{57}$ whereas more moderate energy restriction, ie, $1600-1800 \mathrm{kcal} /$ day was not associated with ketonemia. ${ }^{58}$ Longer-term studies of energy restriction were not powered to evaluate effects on birthweight, although the rate of fetal growth, need for insulin, and amount of insulin eventually needed for some women were reduced. ${ }^{59}$ When obese women consume at least $25 \mathrm{kcal} / \mathrm{kg} /$ day, ketosis and intrauterine growth retardation do not occur. ${ }^{58}$ Therefore, the ADA encourages obese women $\left(\mathrm{BMI} \geq 30 \mathrm{~kg} / \mathrm{m}^{2}\right)$ to reduce their caloric intake by $30 \%,{ }^{7}$ while ACOG notes that further evidence is needed. ${ }^{8}$

The composition of the calories to be consumed is controversial. In one study, low carbohydrate diets were associated with fewer macrosomic infants, cesarean deliveries, and pharmacotherapy. ${ }^{60}$ However, another study found that high carbohydrate diets were, unexpectedly, associated with lower macrosomia rates, possibly because diets rich in complex carbohydrates and low glycemic foods may enable greater 
carbohydrate consumption. ${ }^{61}$ In support of this hypothesis, another study found that a low glycemic diet was associated with lower insulin use, although the study was not powered to determine effects on birthweight. ${ }^{62}$ In the face of this uncertainty, the ADA recommends the proportion of dietary carbohydrate be limited to about $40 \%-45 \%$ of total caloric consumption, ${ }^{63}$ while others note that carbohydrate consumption can be higher if they are complex. ${ }^{59}$

Currently, no organizations recommend specific amounts and sources of fat consumption for women with GDM. Polyunsaturated fatty acids may be protective against impaired glucose tolerance, whereas saturated fatty acids can increase glucose and insulin levels in women with GDM, ${ }^{64}$ but the exact amounts that might be beneficial, and furthermore beneficial in a GDM pregnancy, are not known.

\section{Physical activity}

Up to $39 \%$ of women with GDM cannot meet glucose targets through diet alone. ${ }^{65}$ Physical activity may improve glucose tolerance by improving insulin sensitivity ${ }^{66}$ involving muscle glucose uptake and glycogen synthesis, ${ }^{67}$ and therefore physical activity is a logical adjunct to dietary therapy. Historically, this potential benefit has been outweighed by the concern that exercise could theoretically lead to an increase in secretion of insulin, free fatty acids, and ketones, with a concomitant decrease in glucose levels. ${ }^{7,68}$ However, several small studies that demonstrate the safety of exercise during pregnancy and the association with either better cardiorespiratory fitness or mean glucose values. .,68-70 $^{-1}$

General guidelines encourage at least 30 minutes of physical activity on several days a week, or the equivalent. ${ }^{7,68}$ More tailored activity based on women's fitness and prepregnancy physical activity levels might be more effective at addressing glucose and weight targets in individual women, although the study addressing this question is yet to be conducted. ${ }^{71}$

\section{Pharmacotherapy}

If women cannot achieve glycemic goals with the strategies outlined above, pharmacotherapy with insulin is recommended. ${ }^{7}$ The mainstay of pharmacotherapy during pregnancy has been neutral protamine Hagedorn insulin for basal injections 2-4 times daily. Continuous insulin infusion of a rapid-acting insulin analog, such as lispro and aspart, are sometimes used instead if patients are able to check their blood glucose levels and glucose monitoring devices frequently. ${ }^{72}$ These analogs have not been well studied during GDM pregnancy, in that outcome data are not available, ${ }^{7}$ although analogs are associated with a decrease in hypoglycemic episodes and greater patient satisfaction. ${ }^{72}$

Insulin may be administered according to the woman's pattern of glucose administration. If the fasting glucose is elevated in the morning, evening neutral protamine Hagedorn insulin can be used, at a typical starting dose of 0.2 units $/ \mathrm{kg}$ body weight. If postprandial glucoses are elevated, shortacting insulins at doses of 1.5 units per $10 \mathrm{~g}$ per carbohydrate per breakfast and 1.0 units per $10 \mathrm{~g}$ per carbohydrate per lunch and dinner can be used. If both pre- and postprandial glucoses are elevated, four injections per day can be used at 0.9-1.0 units $/ \mathrm{kg}$. Insulin can be divided into 50\% neutral protamine Hagedorn insulin and $50 \%$ as three preprandial rapid-acting injections. These regimens are largely adapted from those used in women with preconception diabetes during pregnancy. ${ }^{73}$

Theoretically, the use of oral agents is appealing, in that subcutaneous injections can be avoided, leading to subsequent improvement in glucose levels, as well as patient satisfaction. While use in the community is common, ${ }^{74}$ oral sulfonylureas, particularly glyburide, have not yet been endorsed by the ADA or the ACOG, due to concerns about impact upon perinatal outcomes. The MiG trial found that $46 \%$ of women randomized to metformin eventually required additional insulin, although the adverse outcome rate was not higher in the metformin group. ${ }^{5}$ In one trial of glyburide users versus insulin users, both groups attained similar rates of glycemic control. ${ }^{75}$ No differences in macrosomia and neonatal hypoglycemia were seen, but maternal and fetal outcomes were secondary outcomes and the study was not powered to detect differences.

\section{Fetal monitoring}

Although specific antepartum assessment techniques are not specifically endorsed by ACOG and other organizations, their use in clinical practice is routine. The most commonly used test is the twice-weekly nonstress test, which consists of continuous external fetal heart rate monitoring and evaluation of amniotic fluid volume. ${ }^{76}$ If the results of such testing are not reassuring, more specific testing, such as the biophysical profile, ${ }^{77}$ contraction stress test, ${ }^{78}$ or umbilical artery Doppler evaluations $^{79}$ can help determine if fetal hypoxia is present. There is a wide range of practice due to lack of evidence for specific strategies and the timing of such strategies. ${ }^{80}$ In GDM pregnancies that are managed without pharmacotherapy and are normoglycemic, such testing commonly begins at approximately 37 weeks, and in more complicated GDM pregnancies, testing commonly begins at approximately 
32 weeks. Intervention in the form of induction can then occur if indicated. ${ }^{30}$ As noted earlier, the evidence base will probably always be somewhat limited by the low rate of stillbirth and the unlikeliness of a randomized trial to test such strategies.

Fetal ultrasonography is generally performed for assessment of fetal growth, as well as for detection of anomalies. The first ultrasound usually occurs at diagnosis of GDM. ${ }^{1}$ Thereafter, it may occur as often as every three weeks, particularly in the presence of comorbidities that can also affect fetal growth such as hypertension, but the timing and frequency are controversial. Maternal obesity limits the accuracy of such testing for anomaly detection; in one study, at 25 weeks' gestation, women with BMIs in the 90th percentile had visualization of fetal structures decreased by about a tenth to a third.$^{81}$ Visualization may be improved with transumbilical approaches or in the second trimester in obese women. ${ }^{82}$ However, even with these limitations, the use of ultrasound can decrease the rate of shoulder dystocia by leading to induction of labor for fetal growth above the 90th percentile at 38 weeks or for fetal weights estimated at or above $4250 \mathrm{~g} .{ }^{83}$

Women with GDM may also engage in "daily kick counts" during the last 10 weeks of pregnancy, with more intensive medical evaluation applied in the case of reduction in fetal movement. ${ }^{84}$ The value of this strategy as a substitute for the more intensive monitoring outlined in the previous paragraph is unknown, and both maternal self-monitoring, as well as a nonstress test, are generally both performed. ${ }^{84}$

\section{Labor management}

There is no consensus on the timing of induction of labor in women with GDM, with its mixture of risks and benefits. Risks include cesarean section with its attendant complications, and benefits include decreased fetal growth, dystocia, and stillbirth. ${ }^{30}$ Currently, women with GDM are monitored closely for excess fetal growth, and induction is usually recommended when women exceed those parameters, with fairly low thresholds to induce or after 40 weeks.

During induced and spontaneous labor, insulin requirements generally increase due to the work of the uterus. However, women may still require continuous insulin, particularly if they required pharmacotherapy during the pregnancy. In these women, glucose is monitored continuously or at least every two hours, and insulin infusions are started when the woman is mildly hyperglycemic at $120 \mathrm{mg} / \mathrm{dL}$. Insulin infusions are preferred to subcutaneous injections due to women's rapidly changing caloric needs during labor and unpredictable oral intake. Conversely, dextrose infusions are given when women's glucose levels drop below $60 \mathrm{mg} / \mathrm{dL}$ or when they experience symptoms of hypoglycemia. As with insulin use during pregnancy, insulin and glucose management during labor are based primarily on trials of women with preconception diabetes. ${ }^{85}$

\section{Postpartum management and treatment options Postpartum screening for diabetes}

Because up to $10 \%$ of GDM cases actually represent undiagnosed diabetes, postpartum glucose testing can confirm continuing glucose intolerance. ${ }^{86}$ Therefore, several organizations endorse some type of glucose screening at the postpartum visit. ${ }^{1,7,87}$ As with the tests used for the index GDM diagnosis, there is not complete consensus on the optimal test. Fasting glucose and postprandial glucose levels will detect glucose intolerance in different populations, and only about one-third of the glucose-intolerant population will have defects in both compared with one or the other test. ${ }^{88,89}$ However, the impact of performing a 2-hour $75 \mathrm{~g}$ OGTT as opposed to a single fasting glucose upon maternal outcomes and outcomes of future pregnancies has not been examined. Similarly, the hemoglobin A1c assay will detect an overlapping but not identical population of glucose-intolerant women, ${ }^{90}$ but it is unknown if the women diagnosed as glucose-tolerant by the hemoglobin A1c and intolerant by the 2-hour glucose value will suffer from misclassification. At the time of this review, the ADA has endorsed the use of the hemoglobin A1c as a diabetes screen, ${ }^{89}$ and no studies have examined its diagnostic properties compared with other glucose screens in the postpartum GDM population.

\section{Contraception and breastfeeding}

Breastfeeding encourages weight loss and, apart from weight, is associated with better glucose tolerance and reduced incidence of future metabolic syndrome. ${ }^{91,92} \mathrm{~A}$ review of all the potential benefits of breastfeeding are beyond the scope of this article, and the reader is referred to Gunderson's review. ${ }^{93}$ Breastfeeding is associated with a lower risk of overweight and obesity during childhood and adolescence in the general population, but whether breastfeeding has the same protective effects among women with GDM has not been studied. ${ }^{94}$ Due to the other benefits of breastfeeding (upon other offspring outcomes aside from weight and glucose) and the absence of risk associated with breastfeeding, breastfeeding is generally encouraged for women with histories of glucose intolerance. $^{94}$ 
Breastfeeding without supplementation will lead to lactational amenorrhea, a highly effective contraceptive strategy in the first six months postpartum. ${ }^{95}$ Women must be exclusively breastfeeding in order to prevent ovulation, and because return to fertility may precede menstruation, backup barrier methods are encouraged..$^{96}$ Estrogen-progestin based methods, including most birth control pills, as well as the ethinyl estradiol-etonorgestrel ring and patch, do not appear to affect glucose levels adversely and are highly effective..$^{96,97}$ Intrauterine devices are the most commonly used effective contraception outside of the US, and the levonorgestrel form has not been demonstrated to have adverse effects upon glucose among women with type 1 diabetes. ${ }^{98}$ This progestin intrauterine device leads to less menorrhagia than the copper intrauterine device, ${ }^{98}$ and therefore may be preferred by women with heavy menses. Progestin-only strategies which significantly raise systemic progestin levels, either in pill or injection form, have been shown to increase the risk of glucose intolerance in specific populations and are therefore not first-line choices. ${ }^{97}$

\section{Lifestyle modification}

The majority of women with histories of GDM are overweight or obese, have sedentary lifestyles, and consume few vegetables and fruits. ${ }^{99}$ In contrast, weight targets of $<25 \mathrm{~kg} / \mathrm{m}^{2}$, physical activity of $\geq 2.5$ hours/week of moderate aerobic activity or 75 minutes/week of vigorousintensity aerobic activity or an equivalent, ${ }^{100}$ and consumption of five or more servings of fruits and vegetables per day, are recommended. ${ }^{99}$

In the Diabetes Prevention Program, women with GDM approximately a decade after their last pregnancy were able to decrease their diabetes risk with a goal of weight reduction of $7 \%$ of their baseline weight. ${ }^{101}$ In turn, this weight loss was achieved through increased physical activity and attention to caloric reduction and calorie quality.

Similarly, in the immediate postpartum period, caloric reduction and weight loss can be achieved. However, evidence from randomized trials is lacking for GDM women. Among overweight and obese women, randomization to a 12-week postpartum exercise program was not associated with significant weight loss. ${ }^{102}$ In contrast, a combination of both diet and physical activity was associated with weight loss in other randomized studies, suggesting that both caloric restriction, as well as physical activity, are needed to reduce weight. ${ }^{103,104}$

The high attrition levels in these studies underline the difficulty of engaging in any intervention in the postpartum period. This difficulty may extend for as long as a decade; in the Diabetes Prevention Program, attrition was low, but adherence to lifestyle intervention was lower at younger ages. ${ }^{101}$ Women with histories of GDM had less success with lifestyle intervention than women without histories of GDM, although they differed only in age, ie, 43 years in the GDM women compared with 51 years in the women without GDM. Women with and without GDM who were randomized to lifestyle changes both increased activity in the first year of the intervention, but this improvement was not sustained in the GDM women; similarly, the weight loss achieved in the first year was less sustained in the GDM women than in the women without GDM. It is possible that the younger age of the GDM population was associated with younger children and the greater caregiving demands associated with younger children, thus leading to decreased adherence, but this information was not collected as part of the trial.

Currently, medications are not recommended for the prevention of diabetes among women with recent GDM. The Troglitazone in Prevention of Diabetes Study found that randomization to a thiazolidinedione was associated with a decreased risk of diabetes among women with recent GDM, ${ }^{105}$ but the trial was discontinued due to the side effects of troglitazone, and the drug was subsequently withdrawn from the market. Metformin may offer a reasonable alternative for women with histories of GDM who have impaired glucose tolerance and who are overweight. Currently, no organizations endorse it for this purpose among women with recent GDM, who are usually in their fourth decade of life and might require use of the drug for decades. Moreover, women with GDM are, by definition, of child-bearing age, and metformin could potentially impact outcomes in future pregnancies.

\section{Conclusions}

If recent recommendations for diagnosis are adopted, GDM is poised to become one of the most common comorbidities of pregnancy. Even if current diagnostic criteria remain unchanged, the prevalence of GDM will continue to increase as obesity rates rise. While broad consensus exists on the association between glucose levels and adverse perinatal and postpartum outcomes in the mother and offspring, there is disagreement between medical organizations on strategies for monitoring and treatment. Close attention to fetal growth and stress in conjunction with maternal glucose and weight monitoring during pregnancy, followed by delivery if targets are exceeded, appear to minimize adverse outcomes. 
Further studies in the prenatal period are needed to establish the optimal glucose and weight targets to minimize adverse outcomes, and the timing and dose of pharmacotherapy. Further studies in the postpartum period are also needed to establish the intervals and assays for postpartum screening and the effectiveness of interventions for diabetes prevention in the mother and offspring. Such attention could potentially offset the significant morbidity associated with chronic diabetes by leveraging the greater contact women have with medical care during pregnancy.

\section{Disclosure}

The author reports no conflicts of interest in this work.

\section{References}

1. Metzger B, Buchanan T, Coustan D, et al. Summary and recommendations of the Fifth International Workshop-Conference on Gestational Diabetes Mellitus. Diabetes Care. 2007;30(2):S251-S260.

2. Ferrara A, Kahn H, Quesenberry C, Riley C, Hedderson M. An increase in the incidence of gestational diabetes mellitus: Northern California. Obstet Gynecol. 2004;103(3):526-533.

3. HAPO Study Cooperative Research Group. Hyperglycemia and adverse pregnancy outcomes. N Engl J Med. 2008;358(19):1991-2002.

4. Crowther C, Hiller J, Moss J, et al. Effect of treatment of gestational diabetes mellitus on pregnancy outcomes. NEngl J Med. 2005; 352(24): 2477-2486.

5. Rowan J, Hague W, Gao W, Battin M, Moore M; MiG Trial Investigators. Metformin versus insulin for the treatment of gestational diabetes. N Engl J Med. 2008;358(19):2003-2015.

6. Hadden D. A historical perspective on gestational diabetes. Diabetes Care. 1998;21:B3-B4.

7. American Diabetes Association. Gestational diabetes mellitus. Diabetes Care. 2004;27 Suppl 1:S88-S90.

8. ACOG Practice Bulletin. Clinical management guidelines for obstetrician-gynecologists. Obstet Gynecol. 2001;98(3):525-538.

9. World Health Organization. Definition and diagnosis of diabetes mellitus and intermediate hyperglycemia: A report of WHO/IDF consultation. Geneva: World Health Organization; 2006.

10. IADSPG Consensus Panel. International Association of Diabetes and Pregnancy Study Groups recommendations on the diagnosis and classification of hyperglycemia in pregnancy. Diabetes Care. 2010;33(3): 676-682.

11. Lawrence J, Contreras R, Chen W, Sacks D. Trends in the prevalence of pre-existing diabetes and gestational diabetes mellitus among a racially/ ethnically diverse population of pregnant women, 1999-2005. Diabetes Care. 2010;33(3):569-576.

12. O’Sullivan J. Diabetes mellitus after GDM. Diabetes. 1991; 29 Supp1 2: $131-135$.

13. ACOG Committee Opinion. Obesity in pregnancy: ACOG Committee Opinion Number 315, 2005 Sep. Obstet Gynecol. 2005;106(3): $671-675$.

14. Institute of Medicine and National Research Council Committee to Reexamine IOM Pregnancy Weight Guidelines, editor. Weight Gain During Pregnancy: Reexamining the Guidelines. Washington, DC: National Academies Press; 2009.

15. Kim S, England L, Wilson H, Bish C, Satten G, Dietz P. Percentage of gestational diabetes mellitus attributable to overweight and obesity. Am J Public Health. 2010;100(6):1047-1052.

16. HAPO Study Cooperative Research Group. Hyperglycemia and Adverse Pregnancy Outcome (HAPO) study: Preeclampsia. Am JObstet Gynecol. 2010;202(3):255.e251-e257.
17. Seely E, Solomon C. Insulin resistance and its potential role in pregnancy-induced hypertension. J Clin Endocrinol Metab. 2003;88(6): 2393-2398.

18. Anyaegbunam A, Scarpelli S, Mikhail M. Chronic hypertension in gestational diabetes: Influence on pregnancy outcome. Gynecol Obstet Invest. 1995;39(3):167-170.

19. ACOG Committee on Practice Bulletins - Obstetrics. ACOG practice bulletin. Management of preterm labor. Int J Gynaecol Obstet. 2003;82(1):127-135.

20. Sokol R, Blackwell S; American College of Obstetricians and Gynecologists Committee on Practice Bulletins. ACOG practice bulletin: Shoulder dystocia. Int J Gynaecol Obstet. 2003;80(1):87-92.

21. Dumont C, Forin V, Asfazadourian H, Romana C. Function of the upper limb after surgery for obstetric brachial plexus palsy. J Bone Joint Surg Br. 2001;83(6):894-900.

22. Metha S, Blackwell S, Bujold E, Solol R. What factors are associated with neonatal injury following shoulder dystocia? J Perinatol. 2006;26(2):85-88.

23. HAPO Study Cooperative Research Group. Hyperglycemia and Pregnancy Outcome Study: Associations with neonatal anthropometrics. Diabetes. 2009;58(2):453-459.

24. O'Sullivan J, Charles D, Mahan C, Dandrow R. Gestational diabetes and perinatal mortality rate. Am J Obstet Gynecol. 1973;116(7):901-904.

25. Girz B, Divon M, Merkatz I. Sudden fetal death in women with wellcontrolled intensively monitored gestational diabetes. J Perinatol. 1992; 12(3):229-233.

26. HAPO Study Cooperative Research Group. Hormonal and metabolic factors associated with variations in insulin sensitivity in human pregnancy. Diabetes Care. 2010;33(2):356-360.

27. Landon M, Spong C, Thom E, et al. A multicenter, randomized trial of treatment of mild gestational diabetes. $N$ Engl J Med. 2009;361(14): 1339-1348.

28. Ferrara A, Weiss N, Hedderson M, et al. Pregnancy plasma glucose levels exceeding the American Diabetes Association thresholds, but below the National Diabetes Data Group thresholds for gestational diabetes mellitus, are related to the risk of neonatal macrosomia, hypoglycaemia, and hyperbilirubinaemia. Diabetologia. 2007;50(2):298-306.

29. Sermer M, Naylor C, Kenshole A, et al. The Toronto Tri-Hospital Gestational Diabetes Project: A preliminary review. Diabetes Care. 1998;21 Suppl 2:833-842.

30. Witkop C, Neale D, Wilson L, Bass E, Nicholson W. Active compared with expectant delivery management in women with gestational diabetes: A systematic review. Obstet Gynecol. 2009;113(1):206-217.

31. Declercq E, Barger M, Cabral H, et al. Maternal outcomes associated with planned primary cesarean births compared with planned vaginal births. Obstet Gynecol. 2007;109(3):669-677.

32. Simpson E, Lawrenson R, Nightingale A, Farmer R. Venous thromboembolism in pregnancy and the puerperium: Incidence and additional risk factors from a London perinatal database. BJOG. 2001;108(1): 56-60.

33. Kennare R, Tucker G, Heard A, Chan A. Risk of adverse outcomes in the next birth after a first cesarean delivery. Obstet Gynecol. 2007;109 (2 Pt 1):270-276.

34. Wall P, Deucy E, Glantz J, Pressman E. Vertical skin incisions and wound complications in the obese parturient. Obstet Gynecol. 2003;102(5 Pt 1):952-956.

35. Wolfe H, Gross T, Sokol R. Determinants of morbidity in obese women delivered by cesarean. Obstet Gynecol. 1988;71(5):691-696.

36. Kjos S, Berkowitz K, Kung B. Prospective delivery of reliably dated term infants of diabetic mothers without determination of fetal lung maturity: Comparison to historical control. J Mat Fetal Neonat Med. 2002;12(6):1-5.

37. Pedersen J. Weight and length at birth in infants of diabetic mothers. Acta Endocrinol. 1954;16(4):330-342.

38. Catalano P, Thomas A, Huston-Presley L, Amini S. Increased fetal adiposity: A very sensitive marker of abnormal in-utero development. Am J Obstet Gynecol. 2003;189(6):1698-1704. 
39. Catalano P, Kirwan J, Haugel-de Mouzon S, King J. Gestational diabetes and insulin resistance: Role in short- and long-term implications for mother and fetus. J Nutr. 2003;133(5 Suppl 2):S1674-S1683.

40. Dabelea D. The predisposition to obesity and diabetes in offspring of diabetic mothers. Diabetes Care. 2007;30 Suppl 2 :S169-S174.

41. Pettitt D, Nelson R, Saad M, Bennett P, Knowler W. Diabetes and obesity in the offspring of Pima Indian women with diabetes during pregnancy. Diabetes Care. 1993;16(1):310-314.

42. Silverman B, Metzger B, Cho N, Loeb C. Impaired glucose tolerance in adolescent offspring of diabetic mothers: Relationship to fetal hyperinsulinism. Diabetes Care. 1995;18(5):611-617.

43. Dabelea D, Mayer-Davis E, Lamichhane A, et al. Association of intrauterine exposure to maternal diabetes and obesity with Type 2 diabetes in youth: The SEARCH case-control study. Diabetes Care. 2008;31(7): $1422-1426$

44. Meigs J, Cupples A, Wilson P. Parental transmission of Type 2 diabetes: The Framingham Offspring Study. Diabetes. 2000;49(12): 2201-2217.

45. Gillman M, Rifas-Shiman S, Berkey C, Field A, Colditz G. Maternal gestational diabetes, birth weight and adolescent obesity. Pediatrics. 2003;111(3):221-226.

46. Boney C, Verma A, Tucker R, Vohr B. Metabolic syndrome in childhood: Association with birth weight, maternal obesity, and gestational diabetes mellitus. Pediatrics. 2005;115(3):e290-e296.

47. Harris M. Gestatonal diabetes may represent discovery of pre-existing glucose intolerance. Diabetes Care. 1988;11(5):402.

48. Buchanan T, Xiang A, Peters R, et al. Response of pancreatic beta-cells to improved insulin sensitivity in women at high risk for type 2 diabetes. Diabetes. 2000;49(5):782-788.

49. Kim C, Newton K, Knopp R. Gestational diabetes and incidence of Type 2 diabetes mellitus: A systematic review. Diabetes Care. 2002;25(10):1862-1868.

50. Bellamy L, Casas J, Hingorani A, Williams D. Type 2 diabetes mellitus after gestational diabetes: A systematic review and meta-analysis. Lancet. 2009;373(9677):1773-1779.

51. Cheung N, Byth K. Population health significance of gestational diabetes. Diabetes Care. 2003;26(7):2005-2009.

52. Carr D, Utzschneider K, Hull R, et al. Gestational diabetes mellitus increases the risk of cardiovascular disease in women with a family history of Type 2 diabetes. Diabetes Care. 2006;29(9): 2078-2083.

53. Shah B, Retnakaran R, Booth G. Increased risk of cardiovascular disease in young women following gestational diabetes. Diabetes Care. 2008;31(8):1668-1669.

54. Landon M, Thom E, Cpong C; Network MFMU. The NICHD MFMUNetwork randomized clinical trial in progress: Standard therapy vs. no therapy for mild gestational diabetes mellitus. Diabetes Care. 2007; 30 Suppl 2:S194-S199.

55. Ellis S, Speroff T, Dittus R, Brown A, Pichert J, Elasy T. Diabetes patient education: A meta-analysis and meta-regression. Patient Educ Couns. 2004;52(1):97-105.

56. American Diabetes Association. Standards of medical care in diabetes: Position statement. Diabetes Care. 2010;33 Suppl 1:S11-S61.

57. Magee M, Knopp R, Benedetti T. Metabolic effects of 1200-kcal diet in obese pregnant women with gestational diabetes. Diabetes. 1990;39(2):234-240.

58. Algert S, Shragg P, Hollingsworth D. Moderate caloric restriction in obese women with gestational diabetes. Obstet Gynecol. 1985;65(4):487-491.

59. The Diabetes in Pregnancy Dilemma. In: Mazze R, Langer O, editors. Medical Nutrition Therapy. Maryland: University Press of America; 2006.

60. Major C, Henry M, de Veciana M, Morgan M. The effects of carbohydrate Restriction in patients with diet-controlled gestational diabetes. Obstet Gynecol. 1998;91(4):600-604.

61. Romon M, Nuttens M, Vambergue A, et al. Higher carbohydrate intake is associated with decreased incidence of newborn macrosomia in women with gestational diabetes. J Am Diet Assoc. 2001;101(8):897-902.
62. Moses R, Barker M, Winter M, Petocz P, Brand-Miller J. Can a lowglycemic diet reduce the need for insulin in gestational diabetes mellitus? A randomized trial. Diabetes Care. 2009;32(6):996-1000.

63. Franz M, Bantle J, Beebe C, et al. Evidence-based nutrition principles and recommendations for the treatment and prevention of diabetes and related complications. Diabetes Care. 2003;Suppl 1:S51-S61.

64. Ilic S, Jovanovic L, Pettitt D. Comparison of the effect of saturated and monounsaturated fat on postprandial plasma glucose and insulin concentration in women with gestational diabetes mellitus. Am J Perinatol. 1999;16(9):489-495.

65. Langer O, Berkus M, Brustman L, Anyaegbunam A, Mazze R. Rationale for insulin management in gestational diabetes mellitus. Diabetes. 1991;40 Suppl 2:186-190.

66. Mikines K, Sonne B, Farrell P, Tronier B, Galbo H. Effect of physical exercise on sensitivity and responsiveness to insulin in humans. Am J Physiol. 1988;254(3 Pt 1):E248-E259.

67. Perseghin G, Price T, Petersen K, et al. Increased glucose transportphosphorylation and muscle glycogen synthesis after exercise training in insulin-resistant subjects. $N$ Engl J Med. 1996;335(18): $1357-1362$.

68. ACOG Committee Opinion. Exercise during pregnancy and the postpartum period. Obstet Gynecol. 2002;99(1):171-173.

69. Artal R, Catanzaro R, Gavard J, Mostello D, Friganza J. A lifestyle intervention of weight-gain restriction: Diet and exercise in obese women with gestational diabetes mellitus. Appl Physiol Nutr Metab. 2007;32(3):596-601.

70. Bung P, Artal R, Khodiguian N, Kjos S. Exercise in gestational diabetes. An optional therapuetic approach? Diabetes. 1991;40 Suppl 2: 182-185.

71. Artal R, Lockwood C, Brown H. Weight gain recommendations in pregnancy and the obesity epidemic. Obstet Gynecol. 2010;115(1): $152-155$.

72. Hirsch I. Insulin analogues. N Engl J Med. 2005;352(2):174-183.

73. Nachum Z, Ben-Shlomo I, Weiner E, Shalev E. Twice daily vs four times daily insulin dose regimens for diabetes in pregnancy: Randomised controlled trial. BMJ. 1999;319(7219):1223-1227.

74. Gabbe S, Graves C. Management of diabetes mellitus complicating pregnancy. Obstet Gynecol. 2003;102(4):857-868.

75. Langer O, Conway D, Berkus M, Xenakis E, Gonzales O. A comparison of glyburide and insulin in women with gestational diabetes mellitus. N Engl J Med. 2000;343(16):1134-1138.

76. Evertson L, Gauthier R, Schifrin B, Paul R. Antepartum fetal heart rate testing. I. Evolution of the nonstress test. Am J Obstet Gynecol. 1979; 133(1):29-33.

77. Manning F, Platt L, Sipos L. Antepartum fetal evaluation: Development of a fetal biophysical profile. Am J Obstet Gynecol. 1980;136(6): 787-795.

78. Freeman R, Anderson G, Dorchester W. A prospective multi-institutional study of antepartum fetal heart rate monitoring. II. Contraction stress test versus nonstress test for primary surveillance. Am J Obstet Gynecol. 1982;143(7):778-781.

79. Weiner C. The relationship between the umbilical artery systolic/ diastolic ratio and umbilical blood gas measurements in specimens obtained by cordocentesis. Am J Obstet Gynecol. 1990;162(5): 1198-1202.

80. Ben-Haroush A, Chen R, Hadar E, Hod M, Yogev Y. Accuracy of a single fetal weight estimation at 29-34 weeks in diabetic pregnancies: Can it predict large-for-gestational-age infants at term? Am J Obstet Gynecol. 2007;197(5):497.e491-e496.

81. Wolfe H, Sokol R, Martier S, Zador I. Maternal obesity: A potential source of error in sonographic prenatal diagnosis. Obstet Gynecol. 1990;76(3 Pt 1):339-342.

82. Lantz M, Chisholm C. The preferred timing of second-trimester obstetric sonography based on maternal body mass index. $J$ Ultrasound Med. 2004;23(8):1019-1022.

83. Conway D, Langer O. Elective delivery of infants with macrosomia in diabetic women: Reduced shoulder dystocia versus increased cesarean delivery. Am J Obstet Gynecol. 1998;178(5):922-925. 
84. Flenady V, MacPhail J, Gardener G, et al. Detection and management of decreased fetal movements in Australia and New Zealand: A survey of obstetric practice. Aust N Z J Obstet Gynaecol. 2009;49(4):358-363.

85. ACOG Practice Bulletin. Clinical management guidelines for obstetrician-gynecologists: Pregestational diabetes mellitus. Obstet Gynecol. 2005;105(3):675-685.

86. Kjos S, Buchanan T. Gestational diabetes mellitus. $N$ Engl J Med. 1999;341(23):1749-1756.

87. ACOG Committee on Obstetric Practice. Postpartum screening for abnormal glucose tolerance in women who had gestational diabetes mellitus. Obstet Gynecol. 2009;113(6):1419-1421.

88. Ferrara A, Peng T, Kim C. Trends in postpartum diabetes screening and subsequent diabetes and impaired glucose regulation among women with histories of gestational diabetes mellitus: a TRIAD study. Diabetes Care. 2009;32(2):269-274.

89. American Diabetes Association. Diagnosis and classification of diabetes mellitus. Diabetes Care. 2010;33 Suppl 1:S62-S69.

90. Cowie C, Rust K, Byrd-Holt D, et al. Prevalence of diabetes and highrisk for diabetes using A1c criteria in the US population in 1988-2006. Diabetes Care. 2010;33(3):562-568.

91. Nelson A, Le M, Musherraf Z, Vanberckelaer A. Intermediate-term glucose tolerance in women with a history of gestational diabetes: Natural history and potential associations with breastfeeding and contraception. Am J Obstet Gynecol. 2008;198(6):699.e1-e7.

92. Gunderson E, Jacobs D Jr, Chaing V, et al. Duration of lactation and incidence of the metabolic syndrome in women of reproductive age according to gestational diabetes mellitus status: A 20-year prospective study in CARDIA (Coronary Artery Risk Development in Young Adults). Diabetes. 2010;59(2):495-504.

93. Gunderson E. Breast-feeding and diabetes: Long-term impact on mothers and their infants. Curr Diab Rep. 2008;8(4):279-286.

94. Steube A. Breastfeeding and diabetes - benefits and special needs. Diabetes Voice. 2007;52(1):26-29.

95. Labbok M, Hight-Laukaran V, Peterson A, Fletcher V, von Hertzen H, van Look P. Multicenter study of the Lactational Amenorrhea Method (LAM): I. Efficacy, duration, and implications for clinical application. Contraception. 1997;55(6):327-336.
96. Teal S. Contraception for women with chronic medical conditions. Obstet Gynecol Clin North Am. 2007;34(1):113-126.

97. Damm P, Mathiesen E, Petersen K, Kjos S. Contraception after gestational diabetes. Diabetes Care. 2007;30 Suppl 2:S236-S241.

98. Rogovskaya S, Rivera R, Grimes D, et al. Effect of a levonorgestrel intrauterine system on women with Type 1 diabetes: A randomized trial. Obstet Gynecol. 2005;105(4):811-815.

99. Kieffer E, Sinco B, Kim C. Health behaviors in women with a history of gestational diabetes mellitus in the Behavioral Risk Factor Surveillance System. Diabetes Care. 2006;29(8):1788-1793.

100. Division of Nutrition PA, and Obesity, Centers for Disease Control and Prevention. 2008 Physical Activity Guidelines for Healthy Pregnant or Postpartum Women. 2008. Available from: ://www.cdc. gov/physicalactivity/everyone/guidelines/pregnancy.html. Accessed 2010 Aug 1.

101. Ratner R, Christophi C, Metzger B, et al. Prevention of diabetes in women with a history of gestational diabetes; effects of metformin and lifestyle interventions. J Clin Endocrinol Metab. 2008;93(12):4774-4779.

102. Lovelady C, Nommsen-Rivers L, McCrory M, Dewey K. Effects of exercise on plasma lipids and metabolism of lactating women. Med Sci Sports Exerc. 1995;27(1):22-28.

103. Lovelady C, Garner K, Moreno K, Williams J. The effect of weight loss in overweight, lactating women on the growth of their infants. N Engl J Med. 2000;342(7):449-453.

104. O'Toole M, Sawicki M, Artal R. Structured diet and physical activity prevent postpartum weight retention. JWomen's Health. 2003;12(10): 991-998.

105. Buchanan T, Xiang A, Peters R, et al. Preservation of pancreatic betacell function and prevention of Type 2 diabetes by pharmacological treatment of insulin resistance in high-risk Hispanic women. Diabetes. 2002;51(9):2796-2803.
International Journal of Women's Health

\section{Publish your work in this journal}

The International Journal of Women's Health is an international, peerreviewed open-access journal publishing original research, reports, reviews and commentaries on all aspects of women's healthcare including gynecology, obstetrics, and breast cancer. Subject areas include: Chronic conditions (migraine headaches, arthritis, osteoporosis);

\section{Dovepress}

Endocrine and autoimmune syndromes; Sexual and reproductive health; Psychological and psychosocial conditions. The manuscript management system is completely online and includes a very quick and fair peer-review system. Visit http://www.dovepress.com/ testimonials.php to read real quotes from published authors. 